\title{
The Curies: A Biography of the Most Controversial Family in Science
}

\section{Brian}

Hoboken, NJ: John Wiley \& Sons, Inc., 2005, 438 pages, $\$ 30$
Marie Curie, born Marie Sklodowska, grew up in Poland, a police state under the Russian czar Alexander II. Her mother was headmistress of a prestigious girls' boarding school, and her father, a professor and assistant principal in a boys' school. Her family struggled under a Russian rule determined to eradicate the language, culture, and history of the Polish people. After graduating from high school at the top of her class, Marie Curie worked as a governess until she followed her older sister to Paris to study at the Sorbonne's Faculty of Sciences.

Pierre Curie, on the other hand, was born a Parisian. Both his father and grandfather were physicians. His parents thought that the child Pierre was too sensitive and introspective for the rigid French classroom, and they decided to teach him at home. Growing up for Pierre was difficult, particularly because his father was an outspoken radical siding with the revolutionary Paris Commune, causing him to lose desirable, wealthy patients. At 16 , because of his predisposition to mathematics, Pierre entered the prestigious Sorbonne and received a degree in physics and later worked as a laboratory assistant.

The Curies: A Biography of the Most Controversial Family in Science follows these simple beginnings of Marie and Pierre Curie-how they would meet, marry in 1895, and become one of the most distinguished scientific families in history. Their joint researches into radioactive polonium and radium, painstakingly separated from several tons of pitchblende, earned them the Nobel Prize in physics with Henri Becquerel. Eight years later, Marie Curie earned a second Nobel Prize, in chemistry, for the separation of polonium and radium. Marie became not only the first woman in science to earn 2 Nobel Prizes but also the first woman to be appointed professor at the Sorbonne.

The book is not limited to just the scientific achievements of the Curies; the author also focuses on the lesser known controversial events in their lives. One interesting chapter describes the psychic research the Curies under- went with the famed Italian medium Eusapio Palladino, who would perform séances with Pierre and Marie Curie. Pierre afterward would take notes describing levitating tables and mysterious music heard in the distance. The book also describes how the Curies dealt with the public recognition that accompanied their professional achievements, including the scandalous love affair made public between Marie Curie and her physicist colleague Paul Langevin. The scandal escalated to such heights that many journalists and editors, as well as Langevin himself, fought duels over the honor of Madame Curie. Many wondered how Marie, a dignified and reserved scientist seemingly devoted to her work, could be involved with breaking up homes and dishonoring her name.

The second part of the book follows the accomplishments of their 2 daughters, Irène and Eve, and their son-inlaw Frederic Joliot-Curie. In the tradition of the Curie family, Irène and Frederic Joliot-Curie continued radiation research, eventually earning a Nobel Prize in chemistry for the synthesis of new radioactive elements. In contrast, Eve Curie, not having the scientific predisposition of the rest of her family, sought to make her mark in music. Later, she turned to journalism and provided the most famous biography of her mother. The final chapter of the book discusses the further achievements of the offspring of the Curies.

The Curies: A Biography of the Most Controversial Family in Science is an in-depth look at the scientific tradition produced by 2 generations of Curies. Although, for the general reader, too many details are given at times, the story of the Curies, placed in their historical and political context, is fascinating. I recommend this book to anyone interested in the history of science.

Robert Matthews Stony Brook University Hospital Stony Brook, New York

COPYRIGHT @ 2007 by the Society of Nuclear Medicine, Inc.

DOI: 10.2967/jnumed.107.041780 